\title{
DOE/PC/94 209--7.8
}

Eighth Quarterly Report

Regulation of Coal Polymer Degradation by Fungi

(DE-FG22-94PC94209)

July 28, 1996

Robert L. Irvine

Department of Civil Engineering and Geological Sciences

University of Notre Dame

Notre Dame, Indiana 46556

John A. Bumpus

Department of Chemistry

University of Northern lowa

Cedar Falls, lowa 50614

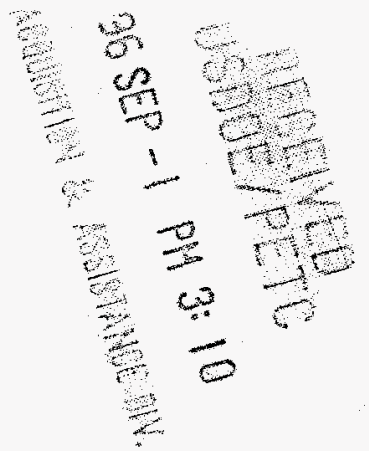

\section{Specific objectives:}

1) To test the hypothesis that coal (leonardite) Solubilization and the subsequent depolymerization of the solubilized coal macromolecules are distinct events in lignin degrading fungi. In addition to $T$. versicolor, Phanerochaete chrysosporium, another lignin degrading fungus that also has the ability to solubilize coal, will be studied.

2) To test the hypothesis that the processes of coal (leonardite) solubilization and coal macro molecule depolymerization in lignin degrading fungi can be regulated by altering the nutritional status of the microorganism. Coal solubilization is expected to occur in nutrient rich media whereas depolymerization of solubilized coal macromolecules is expected to occur in nutrient limited media.

3) To determine the role of extracellular enzymes (laccases, lignin peroxidases and Mn peroxidases) that are secreted by lignin degrading fungi during coal solubilization or coal macro molecule depolymerization.

4) To assess the role of enzymatically generated oxygen radicals, non-radical active oxygen species, veratryl alcohol radicals and $\mathrm{Mn}^{+++}$complexes in coal macro molecule depolymerization.

5) To characterize products of coal solubilization and coal macro molecule depolymerization that are formed by $T$. versicolor and $P$. chrysosporium and their respective extracellular enzymes. Solubilization products formed using oxalic acid and other metal chelators will also be characterized and compared.

\section{Overview}

During this reporting period our efforts focused on: 1) Determining the effect of $\mathrm{pH}$ on coal solubilization by oxalate ion and other biologically important compounds that might function as metal chelators; 2) The role of laccase in low rank coal solubilization and metabolism; 3) Decolorization of soluble coal macromolecule by $P$. chrysosporium and $T$. versicolor in solid agar media and 4) Solubilization of low rank coal in slurry cultures and solid phase reactors containing $P$. chrysosporium.

\section{Methods and materials}

Several of the methods used have been described in previously submitted quarterly DOTRIBUTION OF THIS DOCUMENT IS UNLMTRED ds 


\section{DISCLAIMER}

Portions of this document may be illegible in electronic image products. Images are produced from the best available original document. 


\section{DISCLAIMER}

This report was prepared as an account of work sponsored by an agency of the United States Government. Neither the United States Government nor any agency thereof, nor any of their employees, makes any warranty, express or implied, or assumes any legal liability or responsibility for the accuracy, completeness, or usefulness of any information, apparatus, product, or process disclosed, or represents that its use would not infringe privately owned rights. Reference herein to any specific commercial product, process, or service by trade name, trademark, manufacturer, or otherwise does not necessarily constitute or imply its endorsement, recommendation, or favoring by the United States Government or any agency thereof. The views and opinions of authors expressed herein do not necessarily state or reflect those of the United States Government or any agency thereof. 
reports. Those methods described below are those that have not been described previously.

Laccase production by Trametes versicolor : Isolation and assay of laccase.

To produce laccase, a fungal mat of $T$. versicolor was homogenized in an Osterizer blender with $100 \mathrm{ml}$ of sterile deionized water. Of this mixture $10 \mathrm{~mL}$ was placed in $250 \mathrm{~mL}$ Fahraeus-Reinhammar medium and allowed to grow at ambient room temperature, with agitation on a rotary shaker $(200-250 \mathrm{rpm})$ for $3-4$ days (Fahraeus \& Reinhammar 1967). Laccase production was induced by adding $2.5 \mathrm{ml}$ of a solution of xylidine $(0.024 \mathrm{~g}$ in $10 \mathrm{ml}$ ethanol) followed by continued incubation for another 3-4 days. Laccase activity was assayed as follows. One hundred microliters of the extracellular fluid was placed in a $1.5 \mathrm{~mL}$ cuvette with $1.0 \mathrm{~mL}$ of a solution of catechol $(0.11 \mathrm{~g}$ in $10 \mathrm{ml}$ sodium acetate, $\mathrm{pH} \mathrm{5.0)}$ and the rate of change of absorption at $400 \mathrm{~nm}$ was monitored. Enzyme activity is expressed by the increase in absorbance at $400 \mathrm{~nm}$ per minute/mL. In some experiments, solid leonardite or soluble coal macromolecule was added to preparations of this enzyme to assess the role of laccase in leonardite solubilization and coal macromolecule decolorization and depolymerization.

To isolate laccase, the extracellular fluid from a $260 \mathrm{~mL}$ culture of $T$. versicolor was centrifuged for 30 minutes at 2500 r.p.m in an IEC centrifuge. The supernatant was then concentrated in Centriprep tubes (Amicon) $(10,000$ molecular weight cutoff) until approximately $2 \mathrm{ml}$ of fluid remained. The concentrated fluid was then chromatographed in $50 \mathrm{mM}$ potassium phosphate, $\mathrm{pH} 6.0$ on a PD-10 column (Pharmacia, Uppsala). Fifteen $1.5 \mathrm{ml}$ fractions were collected. Each fraction was assayed for laccase activity, and the absorbance at $280 \mathrm{~nm}$ was acquired for each fraction.

Metabolism of leonardite.

To assess the ability of $T$. versicolor and $P$. chrysosporium to solubilize leonardite, double strength Sabouraud agar was prepared, as was sterile, dry leonardite. Leonardite $(100 \mathrm{mg})$ was placed in 4 petri plates, and Sabouraud agar was poured into these plates as well as into a plate with no leonardite, as a control. Three plates with leonardite were inoculated with $T$. versicolor as was the control plate. One plate with leonardite was left uninoculated as a control. Similar procedures for $P$. chrysosporium. Cultures were placed in a humidified incubator at 27-30 C, and monitored visually for a dark liquid spreading throughout the plate, indicating leonardite solubilization.

Leonardite which had been solubilized by $T$. versicolor and $P$. chrysosporium was harvested by placing the agar on which the fungi had grown in approximately 50 $\mathrm{ml}$ of deionized water. This allowed the solubilized coal macromolecule to diffuse into the deionized water. This mixture was filtered with cheesecloth and the remaining 
liquid was centrifuged at $2500 \mathrm{rpm}$. The supernatant was dialyzed extensively against water and filtered as described above. The retention time for the solubilized macromolecules were obtained by GPC/HPLC. Average molecular weights were determined using a standard curve as described by Polman Quigley (1991).

To assess the ability of $T$. versicolor to depolymerize the solubilized coal macromolecule, double strength Sabouraud agar and double strength Malt agar were prepared. Two solubilized coal macromolecule solutions were prepared. The first was the sterile biomimetically solubilized coal macromolecule alone, and the other was solubilized coal macromolecule with $0.22 \mathrm{~g}$ of diammonium tartrate per $100 \mathrm{ml}$ of macromolecule. The diammonium tartrate provides supplemental nutrient nitrogen that is known to suppress expression of the lignin degrading system of $P$. chrysosporium (Kirk et al., 1978) Cultures were prepared in glass petri plates with 15 $\mathrm{ml}$ of double strength agar and $15 \mathrm{ml}$ of solubilized coal macromolecule or macromolecule with diammonium tartrate. Five plates were prepared with solubilized coal macromolecule and five were prepared with macromolecule solution and diammonium tartrate, while another plate was prepared with Sabouraud agar alone, as a control. Four of the agar and solubilized coal macromolecule plates were inoculated with $T$, versicolor as well as the Sabouraud agar only plate, while one Sabouraud agar plate with solubilized coal macromolecule plate was left uninoculated as a control. The same was performed for the plates with Sabouraud agar and solubilized coal macromolecule with diammonium tartrate. The aforementioned procedure was used with Malt agar for $P$. chrysosporium.

\section{Results}

\section{Effect of $\mathrm{pH}$ on solubilization of leonardite by selected biologically important compounds.}

It has long been known that low rank coals are solubilized by strong base. For example, Fowkes and Frost used $1 \mathrm{~N}$ sodium hydroxide $(\mathrm{pH} 13)$ to solubilize several different lignites. This is an effective method. However, it seems that it would be preferable to develop conditions by which low rank coals are solubilized under less harsh conditions. Indeed, this is one reason why there is considerable interest in the use of microorganisms for such purposes. Although coal solubilization is mediated under strongly basic conditions, it has also been noted that certain Lewis bases are also able to mediate solubilization of low rank coal at $\mathrm{pH}$ values considerably lower that those used to effect solubilization by strong base (Crawford, 1993). The effect of $\mathrm{pH}$ on the ability of oxalate, phosphate and bicarbonate/carbonate ions to mediate solubilization of leonardite is presented in figure 1. The effect of sodium hydroxide concentration on leonardite solubilization is also presented. Of interest is the observation that, in the case of oxalate, bicarbonate/carbonate and phosphate, optimal solubilization appears to occur at $\mathrm{pH}$ values at which the species in question exist as divalent (or higher valent) cations. Indeed, for phosphate, solubilization appears to be a direct function of ionization as the curves for coal solubilization and phosphate ionization virtually overlap (figure 2). The effect in the presence of oxalate is similar 
though not as pronounced (data not shown). However, solubilization does, indeed, increase as a function of divalent oxalate ion. At higher $\mathrm{pH}$, the increase appears to be be due to solubilization due to the presence of a strong base. Solubilization mediated by bicarbonate/carbonate is complicated by the fact that bicarbonate ion appears to be able to mediate substantial amounts of solubilization. However, solubilization by carbonate ion is clearly more effective. Not unexpectantly, high concentration of sodium hydroxide were effective in solubilizing low rank coal. However, very high concentrations inhibited solubilization, possibly due to "salting out" of the coal macromolecule.

These results are important from a biological perspective as several wood rotting fungi grow at acidic $\mathrm{pH}$. For example, the physiological $\mathrm{pH}$ of $P$. chrysosporium appears to be between $\mathrm{pH} 4$ and 5 and the $\mathrm{pH}$ maximum for lignin degradation is approximately $\mathrm{pH} 4.5$ (Kirk et al., 1978). Clearly this $\mathrm{pH}$ range is slightly below that which is optimal for oxalate mediated solubilization of leonardite. Furthermore, it appears that by secreting oxalate ion, fungi are able to solubilize a carbon source that it not normally available.

\section{Effect of Krebs cycle intermediates on solubilization.}

The role of oxalate in the solubilization of low rank coal has been established. However, there are other metabolites that might also have a role in this process if secreted in sufficient quantities. We studied the ability of Krebs cycle intermediates to solubilize leonardite under the same conditions used to study solubilization mediated by oxalate. We showed that, at pH 7.0, $75 \mathrm{mM}$ citrate, oxaloacetate and malate also solubilized substantial quantities of leonardite. Interestingly, citrate and oxaloacetate were slightly better solubilizing agents that oxalate (Table 1).

\section{The role of laccase in low rank coal solubilization and metabolism.}

\section{Laccase production by $T$. versicolor.}

The laccase from the extracellular fluid of $T$. versicolor was concentrated and partially purified by size exclusion column chromatography on a PD-10 column (figure 3). Most of the laccase activity was associated with fraction 3 . According to Fahraeus and Reinhammar (1967), two laccase isozymes represent essentially all of the proteins present in the extracellular fluid of $T$. versicolor that is grown on the growth medium used in this investigation. This method represents a rapid purification by which reasonable amounts of laccase can be obtained. If individual isozymes are required, they can be separated by anion exchange chromatography as described (Fahraeus and Reinhammar, 1967).

Effect of laccase from $T$. versicolor on leonardite solubilization.

It has been reported that the laccase from $T$. versicolor has an important role in solubilization of leonardite. In our investigations, $1.2 \mathrm{mg}$ of leonardite were incubated 
in the presence of a highly activ $(0.261 \mathrm{AU} / \mathrm{min})$ laccase preparation $(1 \mathrm{~mL}$ total volume) for $24 \mathrm{~h}$. Our results indicate that little if any of this material was solubilized under these conditions.

Effect of solubilized coal macromolecule on laccase activity and the effect of laccase on solubilized coal macromolecule.

In previous quarterly reports we have noted that coal macromolecule is a good inhibitor of and a substrate for lignin peroxidases from $P$. chrysosporium. It was, therefore, logical to determine if coal macromolecule might be an inhibitor of or a substrate for the laccase from $T$. versicolor.

Reaction rates for laccase with catechol were approximately the same when the reaction was performed in the absence or presence of soluble coal macromolecule ( $0.011 \mathrm{mg}$ or $0.1 \mathrm{mg}$ solubilized coal macromolecule per $\mathrm{ml}$ ). Furthermore, laccase did not decolorize coal macromolecule. These results suggest that coal macromolecule is not a substrate for or an inhibitor of this enzyme

\section{Decolorization of soluble coal macromolecule by $P$. chrysosporium and $T$. versicolor in solid agar media.}

In a previous quarterly report we noted that in nitrogen limited cultures of $P$. chrysosporium, soluble coal macromolecule was decolorized. A photograph of our most recent experiment is presented in figure 4 . This experiment was of interest because decolorization by this fungus is usually associated with extensive degradation. We were interested in this because it is possible that decolorization may also be used as a surrogate assay for depolymerization. This, however, is still open to question and is a topic of continuing research in our laboratory. It should also be mentioned that we have had some problems duplicating our initial decolorization experiments. Curiously decolorization occurred in glass Petri plates but not plastic Petri plates.

In more recent studies we found that $\mathrm{T}$. versicolor was incapable of decolorizing soluble coal macromolecule in nutrient nitrogen limited or nutrient nitrogen sufficient Sabouraud agar cultures.

\section{Solubilization of low rank coal in slurry cultures and solid phase reactors containing $P$. chrysosporium.}

Effect of Leonardite concentration on lignin peroxidase activity in agitated slurry cultures.

Three concentrations of leonardite ( $0 \%, 0.5 \%$ and $1.0 \%$ (wt./vol.)) were tested in duplicate cultures to assess their effect on lignin peroxidase activity. Shake flask medium $(900 \mathrm{~mL}$ ) was prepared according to Tuisel et al. (1990). From this $90 \mathrm{ml}$ was used to obtain a spore suspension of optical density 0.1 at $610 \mathrm{~nm}$. The spore 
suspension was then mixed with the residual medium to obtain a final inoculated culture of approximately $900 \mathrm{~mL}$. From this, $150 \mathrm{~mL}$ was distributed to each of six flasks. Pre-dried leonardite ( $105 \mathrm{C}$ for 24 hours) was then weighed out in duplicate amounts of 0.75 and $1.5 \mathrm{~g}$ in aluminum weighing dishes and were autoclaved at 121 $\mathrm{C}$ and $15 \mathrm{psi}$ for 45 minutes. Upon cooling, the autoclaved coal was aseptically added to the shake flasks containing inoculated medium to give two flasks at $0.5 \%$ and another two at $1 \%$. The last two of the six flasks which did not have any coal acted as controls in this experiment. The six flasks were then incubated on a shaker table at 37 C for approximately three weeks.

Lignin peroxidase was assayed as follows: $2 \mathrm{~mL}$ samples of extracellular culture fluid was harvested at designated times from each of the six flasks and centrifuged in an Eppendorf mini-centrifuge at $10,000 \mathrm{rpm}$ for 2 minutes. The resulting supernatant was then used to determine the lignin peroxidase activity using the method outlined by Tien and Kirk (1983). Toward the end of the experiment, harvesting extracellular fluid from the agitated cultures was impaired by biomass. Therefore, during this stage of the experiment, extracellular fluid had to be separated using cheese cloth prior to carrying out the steps described above.

Formation of fungal pellets was observed after the second day of operation. The pellet sizes in the coal slurry shake flasks were appreciably smaller than those in the controls and remained consistently smaller throughout the experiment. Lignin peroxidase activity was not observed in all the flasks until the third day of operation ( see attached figure). Lignin peroxidase activity was consistently higher in the control flasks that had no coal. The average LiP activity in the control flasks was approximately $36 \mathrm{U} / \mathrm{L}$ on day 3 and peaked on day 4 at $210 \mathrm{U} / \mathrm{l}$ after which there was a steady decline in activity during the remaining 16 days of operation where the activity dropped to about $45 \mathrm{U} / \mathrm{L}$.

The average LiP activity in the $0.5 \%$ coal slurry flasks were consistently lower than that of the control flasks during the entire course of the experiment. On day 3 the initial LiP activity detected was about $3.5 \mathrm{U} / \mathrm{L}$ compared to that of $36 \mathrm{U} / \mathrm{L}$ in the control. Peak LiP activity of about $142.2 \mathrm{U} / \mathrm{L}$ was observed on day 4. During the remaining days of operation, there was a consistent decline in LiP activity to about $28 \mathrm{U} / \mathrm{L}$ on day 20 . The rate of decline between day 3 and 4 appears to be much slower in the $0.5 \%$ coal slurry flasks. After day 4 the rate of decline in both the controls and the $0.5 \%$ slurry flasks appeared to be comparable.

The LiP activity in the $1 \%$ coal slurry flasks manifested an even lower value relative to the controls or the $0.5 \%$ slurry flasks. Initial activity on day 3 of about 9 U/L was slightly higher than in the $0.5 \%$ slurry flasks. Activity peaked on day 4 at about $79 \mathrm{U} / \mathrm{L}$ after which a steady decline in activity was observed for the remaining sixteen days of operation.

Solubilized product was observed beginning on day 3 in the flasks that had coal. A major portion of the coal slurry was encapsulated in the biomass during pellet 
formation. The remaining coal particles either remained suspended in solution or adhered to the glass wall of the shake flasks. The latter coal particles had to be repeatedly resuspended into solution. The optical density of the centrifuged extracellular culture fluid appeared to increase with increasing amount of coal slurry present. The biomass pellets appeared to absorb some of the solubilized product during the course of the experiment as they gradually adopted the color of the extracellular culture fluid.

Based on the lower LiP activity observed in the shake flasks that contain coal, it appears that coal or soluble coal is inhibitory to the lignin peroxidase. This has been confirmed in vivo as noted in previous quarterly reports. Of interest, however, is the fact that lignin peroxidases were not totally inactivated and that substantial lignin peroxidase activity was observed in coal containing cultures even after extended incubation.

\section{Low rank coal solubilization in solid phase cultures.}

In addition to the slurry phase studies, we have also initiated solid phase biosolubilization studies. A solid phase reactor has been set up at the University of Notre Dame where the initial investigations are underway. This reactor has added advantages over slurry or liquid reactors because it has the potential to process larger quantities of coal. Furthermore it aims to utilize the natural physiological conditions under which the fungus grows, i.e. stationary and undisturbed conditions under which it has been shown to very effective in dismantling the complex lignin structure in wood. Using these natural physiological conditions could have some added benefits to coal biosolubilization.

The solid phase reactor consists of a porous bed reactor constructed from a $1000 \mathrm{~mL}$ separatory funnel. The porous bed, consisting of aquarium stone, occupying approximately $500 \mathrm{~mL}$ and arranged to lay on the long axis of the separatory funnel. Ten $\mathrm{g}$ leonardite mixed with appropriate nutrients is placed on its top surface (approximately 70 square centimeters) as a uniform layer of approximately $4 \mathrm{~mm}$ thick. The reactor was inoculated by bubbling a spore suspension ten times more concentrated than that used for shake flask cultures. Sterile glucose solution (10 g/L) is fed to the bottom of the porous bed which gradually diffuses into the coal/ nutrient mixture above. The incoming stream of air into the reactor was periodically alternated between dry and humid air. Initial results demonstrate that rich mycelial growth is achieved on the coal surface above the porous bed. Solubilized product similar to that observed in our previous studies on agar plates was observed after two weeks. Biosolubilization seems to be continually occurring. The reactor has been in operation for about a month during which continual fungal growth and coal biosolubilization has been occurring despite frequent harvesting of solubilized product via periodic submersion with distilled water. Current focus with regard to this experiment is aimed at method development to measure enzyme activity and increase oxygen transfer through the coal layer and underlying porous bed support. 
Personnel: Mr. Richard Morgan has returned to his position as a high school instructor. He will continue his Masters research part time. Mr. John Senko of St. Vincent College, Latrobe, PA joined our laboratory for the Summer as a UCR intern. Mr. Shawn Roe joined our laboratory as an undergraduate research assistant.

\section{Planned Activities}

During the next reporting period we plan to continue preparation of our manuscript concerning the biomimetic and biological solubilization of low rank coal. We will also be active in the laboratory. Specifically we plan to determine if coal macromolecule decolorization is, indeed, an indication of extensive metabolism and depolymerization. We also plan to further study the role of extracellular enzymes in coal metabolism.

\section{Literature Cited}

Crawford, D.L. Microbial transformations of low rank coal. CRC Press, Boca Raton $223 \mathrm{p}$.

Fahraeus, G. and B. Reinhammar. "Large Scale Production and Purification of Laccase from Cultures of the Fungus Polyporus versicolor and some Properties of Laccase A." Acta Chemica Scandinavica. (1967) 20: 2367-2378.

Kirk, T.K., E. Schultz, W.J. Connors, L.F. Lorenz and J.G. Zeikus (1978) Influence of culture parameters on lignin metabolism by Phanerochaete chrysosporium. Arch. Microbiol. 117:277-285.

Polman, J.K. and D.R. Quigley (1991) Size exclusion chromatography of alkalisolubilized coal. Energy and Fuels 5: 352-353.

Tien, M. and Kirk, T.K. (1983) Lignin-degrading enzyme from Phanerochaete chrysosporium: purification, characterization, and catalytic activity of a unique $\mathrm{H}_{2} \mathrm{O}_{2}$ requiring oxygenase. Proc. Natl. Acad. Sci. USA 81:2280-2284.

Tuisel, H., R. Sinclair, J.A. Bumpus, W. Ashbaugh, B. Brock and S.D. Aust (1990) Lignin peroxidase $\mathrm{H} 2$ from Phanerochaete chrysosporium: purification, characterization and stability to temperature and $\mathrm{pH}$. Arch. Biochem. Biophys. . 279:158-166. 


\section{Figure Legends}

Figure 1. Effect of pH on the solubility of leonardite in the presence of sodium oxalate, phosphate, sodium bicarbonate/carbonate or sodium hydroxide. Twenty $\mathrm{mg}$ of leonardite was incubated on a rotary shaker for $24 \mathrm{~h}$ in $10 \mathrm{ml} 75 \mathrm{mM}$, sodium oxalate, potassium phosphate, sodium bicarbonate/carbonate or sodium hydroxide at the indicated $\mathrm{pH}$. After incubation, the absorbance at $600 \mathrm{~nm}$ was acquired.

Figure 2. Solubilization of leonardite as a function of $\mathrm{pH}$ in the presence of $75 \mathrm{mM}$ potassium phosphate. Data for this illustration is the same as that presented for potassium phosphate in figure 1. In addition, however, this illustration demonstrates that solubilization appears to be a function of hydrogen phosphate ion that is present.

Figure 3. Size exclusion column chromatography of laccase from $T$. versicolor. The extracellular fluid from a $250 \mathrm{~mL}$ culture of $\mathrm{T}$. versicolor was concentrated in Centriprep tubes to $2 \mathrm{~mL}$ and chromatographed on a PD-10 (G-25) column.Fractions $(1.5 \mathrm{ml})$ were collected and laccase activity and $A_{280}$ were determined.

Figure 4. Decolorization of coal macromolecule in malt agar by $P$. chrysosporium. P. chrysosporium was cultured on nutrient nitrogen limited malt agar containing coal macromolecule (162.5 mg/L) (upper left), nutrient nitrogen sufficient malt agar containing coal macromolecule (upper right) and nutrient nitrogen limited malt agar that contained no coal macromolecule (lower right). Uninoculated nutrient nitrogen limited malt agar containing coal macromolecule is also illustrated (lower left). Uninoculated nutrient nitrogen sufficient malt agar that contained coal macromolecule and inoculated nutrient nitrogen sufficient malt agar plates that did not contain coal macromolecule appeared very similar to their nutrient nitrogen limited counterparts and are not illustrated. 
Figure 1

Effect of pH on solubility of leonardite in the presence of sodium oxalate, potassium phosphate, sodium bicarbonate/carbonate or sodium hydroxide

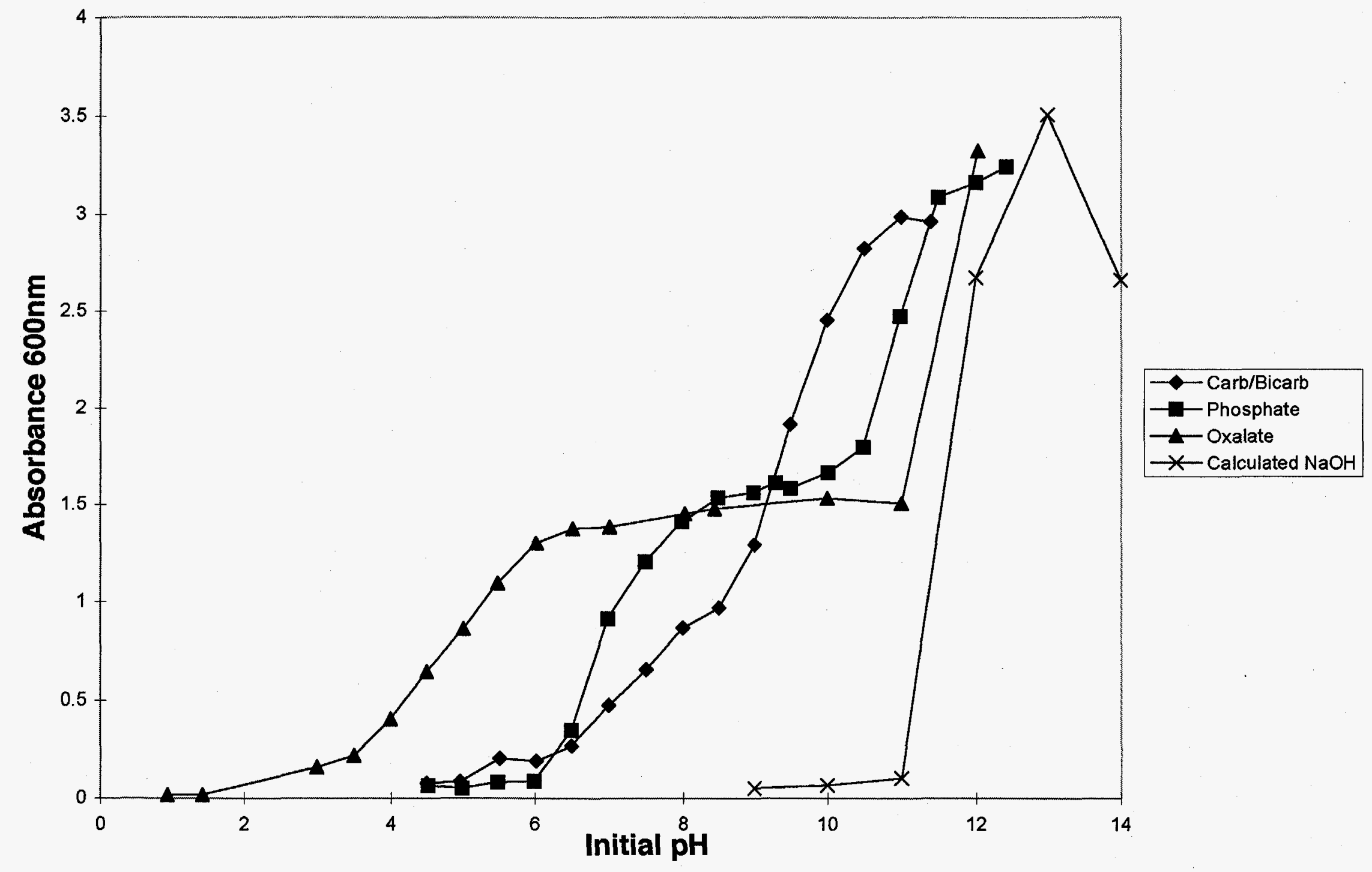


Figure 2- Solubilization of leonardite as a function of $\mathrm{pH}$ in the presence of $75 \mathrm{mM}$ potassium phosphate

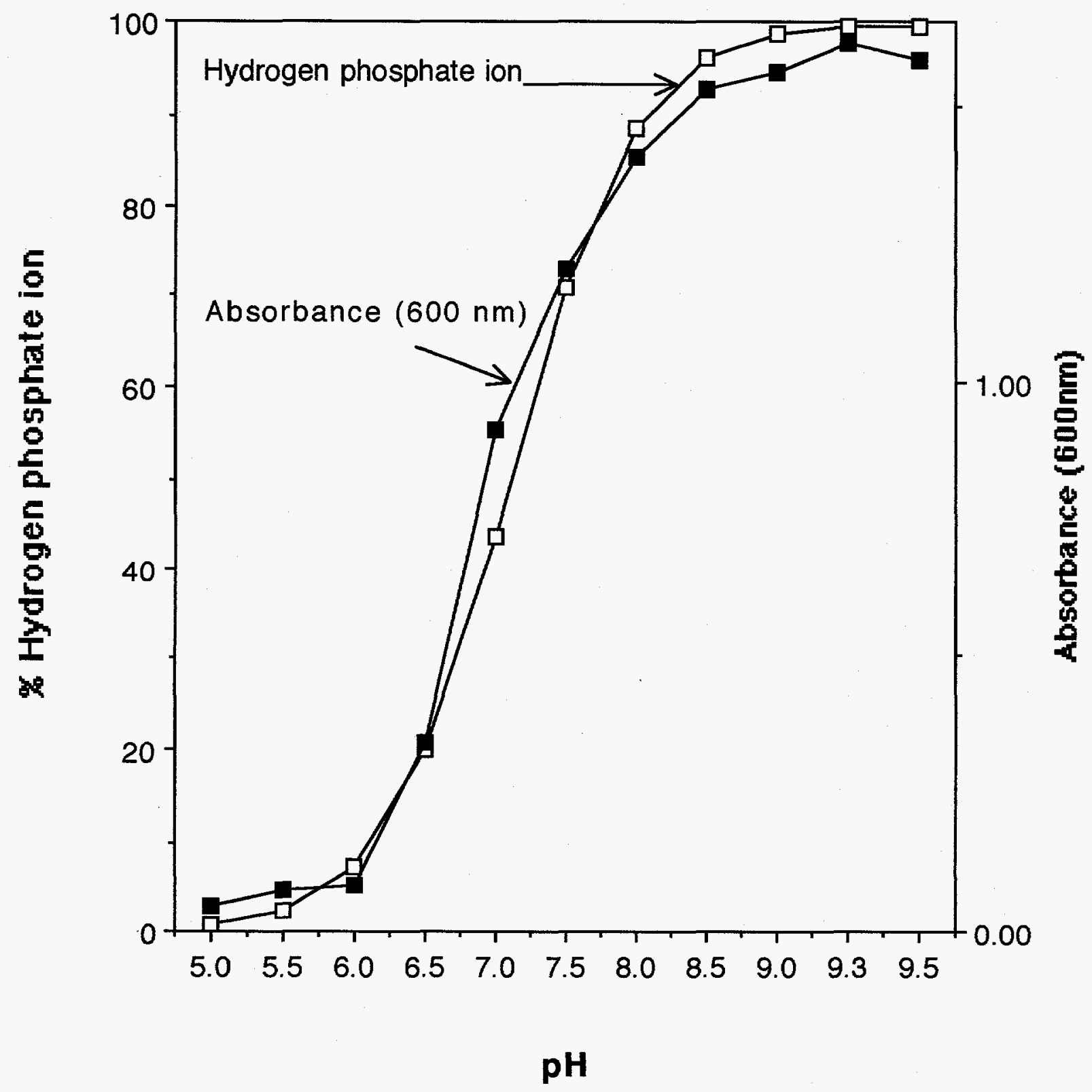




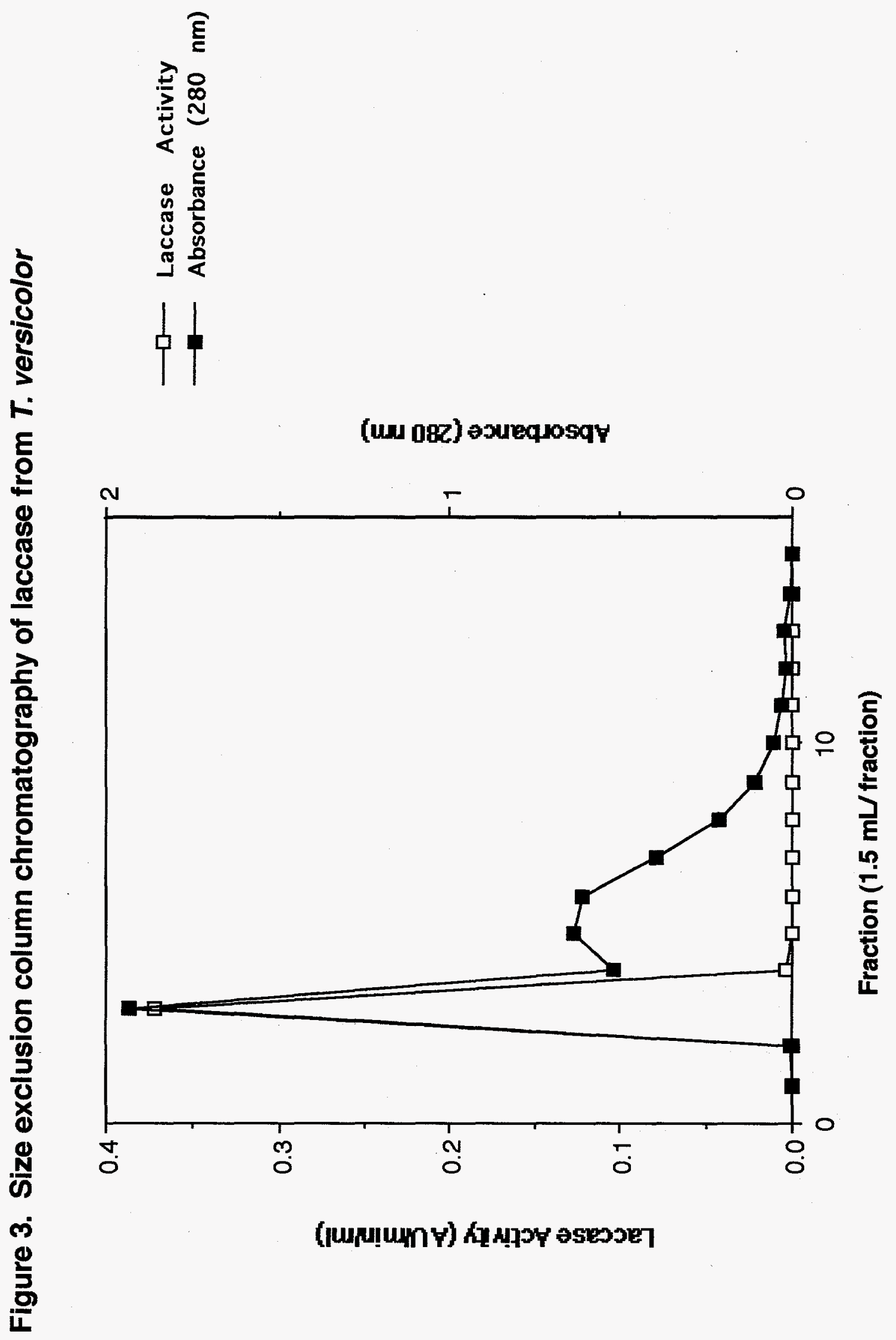


F形

Fisure 4

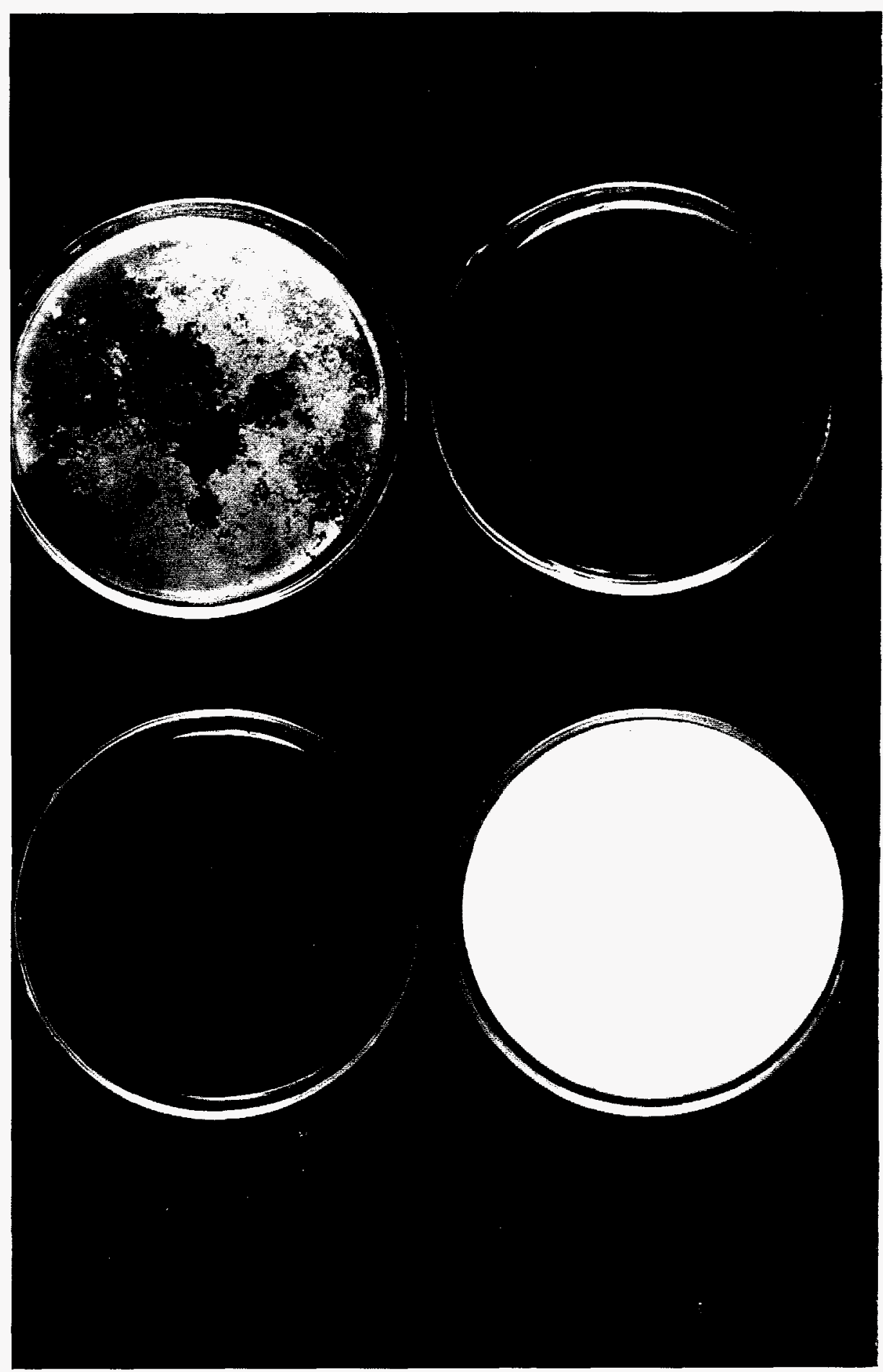


Table 1

Solubilization of leonardite by sodium oxalate and sodium salts of Krebs cycle intermediates.

Compound

Citrate

Oxaloacetate

L-Malate

Succinate

alpha-Ketoglutarate

Fumarate

Oxalate
Absorbance $(400 \mathrm{~nm}) \quad$ Absorbance $(600 \mathrm{~nm})$

10.65

11.34

8.07

1.78

3.03

1.37

10.48
1.59

1.72

1.24

0.37

0.46

0.22

1.38 